\title{
Age as risk factors associated in the genesis of uterovaginal prolapse (UVP)
}

Upendra Pandit, Dibya Shree Malla, Paban Kumar Sharma

\begin{abstract}
Aim: To find out the relationship between utero-vaginal prolapse (UVP) and first vaginal birth at younger age $<22$ years and to identify single most frequently occurred risk factor in study group.

Method: A hospital based descriptive comparative study was carried out in 200 women of age 40- 60 years in two hospitals. One hundred women with UVP were enrolled as case (Group I) and 100 women with similar parity and age group but admitted for other reasons than prolapse were enrolled as comparative group (Group II). Relationship was observed between two groups in their age at first vaginal birth, duration of labour, family history, smoking habit, menopause and BMI.
\end{abstract}

Results: Cases of UVP occurred in younger $<22$ years at first vaginal birth than comparable group (OR $3.41,95 \% \mathrm{Cl} 1.74-6.72, \mathrm{P}=0.00009$ ). The mean of duration of labour pain was $30.85 \pm 26 \mathrm{vs} 18.87 \pm 21.3$ $(P=0.006)$ hours in Group I and Group II respectively. There was increased risk of UVP in women who had family history (OR 2.35; 95\% Cl 1.16-4.78, $\mathrm{P}=0.01$ ).

Conclusion: Single most frequently identified risk factor was young age $<22$ years at first vaginal birth.

Key words: UV prolapse, risk factors, women, first vaginal birth.

\section{Introduction}

Among many problems in women's health UVP in Nepal contributes a major bulk of the reproductive health morbidity. It has been reported that one in every four to ten women suffered from UVP. ${ }^{1,2,3}$ UVP with its related problems not only affects women's health but also social and economic status of women and their family.

There are multiples risk factors involve in the genesis of UVP. They are multiple parity, prolonged labour, menopause etc. ${ }^{4}{ }^{5}$ But Relationship between first vaginal delivery in younger age $(<22$ years of age $)$ and UVP has not been studied extensively. This study is intended to address whether the first vaginal delivery at young age is the single most common risk factor contributing to the genesis of UVP.

\section{Methodology}

A prospective hospital based comparative study was carried out in 200 women of age 40- 60 years in two hospitals. Study was conducted from $14^{\text {th }}$ May 2004 to $14^{\text {th }}$ January 2005 in Prasuti Griha, Thapathali and Patan hospital, Lalitpur Nepal. Among the admitted population, one hundred women with UVP were enrolled as a case (Group I) and 100 women with similar parity and age group but admitted for other reasons than prolapse were enrolled as comparative group (Group II). Women with pregnancy and pregnancy related conditions were excluded. Relationship was observed between two groups in their age at first vaginal birth, duration of labour, family history, smoking habit, menopause and BMI.

\section{Results}

Age at first vaginal birth was compared between Group I and Group II.

Table-1 shows that Group I were more younger, $<22$ years than Group II (OR 3.41, 95\% CI 1.74-6.72, P = 0.00009 ) at first vaginal birth. The odds in favour of the UVP were three times high among women exposed to young age at first vaginal birth $<22$ years than the women not exposed to it. 
Table-I. Distribution of cases according to age at frst vaginal birth

\begin{tabular}{lccccccc}
\hline $\begin{array}{c}\text { Age at first vaginal } \\
\text { birth }\end{array}$ & $\begin{array}{c}\text { Group 1 } \\
\text { UVP }\end{array}$ & $\begin{array}{c}\text { Group II } \\
\text { Other reasons } \\
\text { for admission }\end{array}$ & Total & $\begin{array}{c}\text { Odds } \\
\text { ratio }\end{array}$ & $\begin{array}{c}\text { 95\% } \\
\text { CI }\end{array}$ & $\begin{array}{c}\text { Relative } \\
\text { Risk }\end{array}$ & Pvalue \\
\hline $\begin{array}{l}\text { Age }<22 \text { years at first } \\
\text { vaginal birth }\end{array}$ & 80 & 54 & 100 & 3.41 & $1.74-6.72$ & 1.97 & 0.00009 \\
$\begin{array}{l}\text { Age }>22 \text { years at first } \\
\text { vaginal birth }\end{array}$ & 20 & 46 & 100 & - & - & - & - \\
\hline Total & 100 & 100 & 200 & - & - & - & - \\
\hline
\end{tabular}

Among UVP cases majority of women $54 \%$ who had age $<22$ years at first vaginal birth had UVP started from the first vaginal birth. Figure I shows significant association between young age $<22$ years at first vaginal birth and initiation of UV prolapse from first vaginal birth, OR 3.12 CI $1.02 \& 9.65$, P value 0.02 .

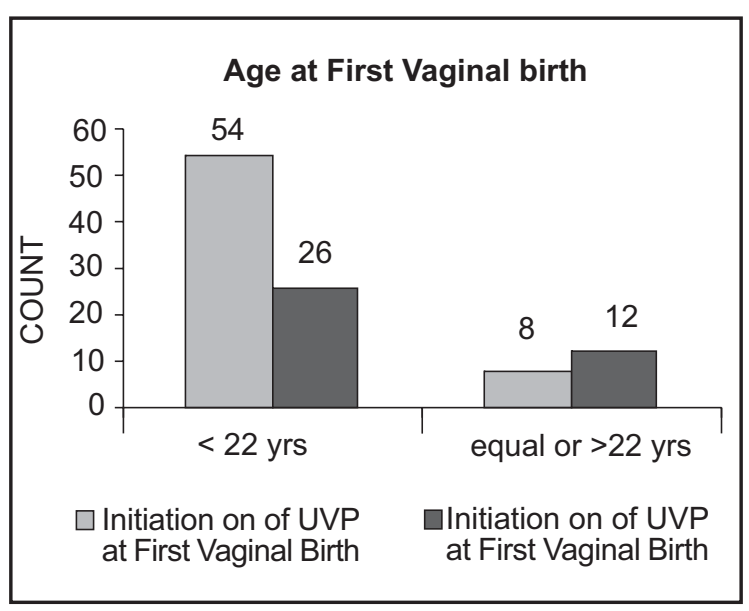

Fig-I. relation between initiation of UVP at first birth and age at first vaginal birth

Figure 2, shows significant association between Prolonged labour $>20$ hours and UVP (OR 2.36 (1.22$4.61, \mathrm{p}=0.006)$. The odds in favour of exposure to $>20$ hours of labour was observed.

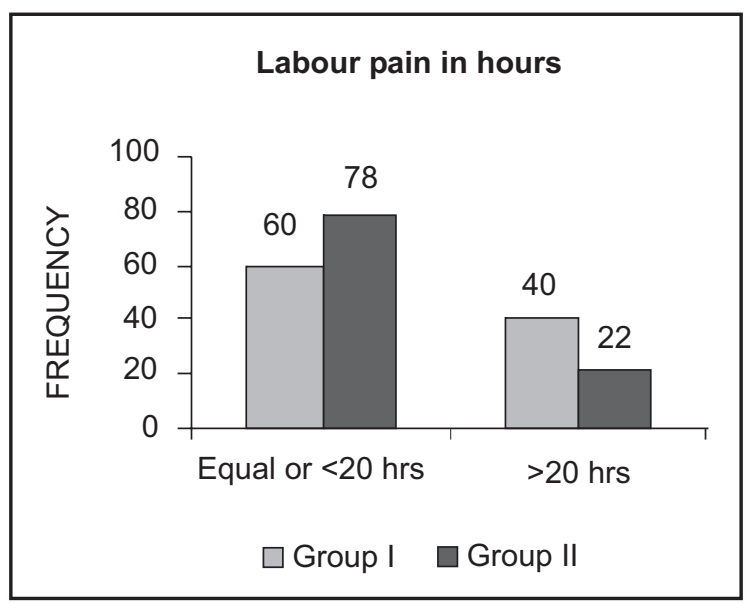

Fig 2. relationship between duration of labour in first vaginal birth

\section{Discussions}

It has been found in various studies that first vaginal birth has the greatest risk which can cause significant pelvic floor stretching and pudendal nerve damage in most of the women in turn may lead to laxity of the pelvic ligaments. ${ }^{6-10}$ The most important finding in this study was that younger age $<22$ years at first vaginal birth has the greatest risk of UVP. This finding supports the hypothesis that first vaginal birth in young age $<22$ years is strongly associated with UVP. Pamela et al reported that cases of UVP were more likely than controls to be younger than 25 years at first delivery $(\mathrm{P}<.001)$ Odds ratio 3.6 CI 2.0-6.6 remained significant risk factor. ${ }^{13}$ This could be because of architectural differences in the bony pelvis of young women with and without uterovaginal prolpase.

Significant association was observed in duration of labor and UVP, OR 2.36 (1.22-4.61), $\mathrm{P}=0.006$. The mean duration of labour pain was $30.85 \pm 26$ vs $18.87 \pm 21.3$ hours in Group I and Group II respectively. It could be because of early bear down from the first stage of labour in home delivery practice that might lead to physical exertion, dehydration and loss of energy during second stage. Duration of labour was more among women with UV prolapse who had younger age at first vaginal birth. The result suggests that women who delivered at a young age had prolonged labour, which may damage pelvic floor sufficiently for early manifestation of UVP in first vaginal birth. This finding supports the statement that prolonged labour causes more tissue trauma, nerve damage, separation or weakness of muscles and ligaments. If these events occur in young pelvis, gravity of the damage might be more and signs and symptoms of prolapse appears early from first vaginal birth.

First-degree family history seemed to be a risk factor for UVP two times more likely than comparable group (group II), which was statistically significant OR 2.35 (95\% CI 1.16-4.78) p value 0.01. F. Chiaffarino et al observed similar finding. They reported that the risk of urogenital prolapse was higher in women with family history of prolapse in mothers and sisters (odds ratio 
3.2 95\% CI 1.1-7.6 and 2.4 95\% CI 1.0-5.6) respectively in comparison with women without family history of prolapse. Cases might be inclined to recall a family history of prolapse more accurately than compare group.

\section{Conclusion}

From these result it can be concluded that age at first vaginal birth $<22$ year was strongly associated with UV prolapse and found as a single most common risk factor in women with UV prolapse. Prolonged labour pain, and family history were other risk factors, which were significantly associated with UV prolapse.

\section{References}

1. Bonetti T.R. An ethnographic Approach to understanding Prolpase Uterus in Western Nepal May 2000. (An academic paper)

2. The joint UNFPA/ WHO (World Health Organization) study was carried out by the Institute of Medicine, Tribhuvan University, Teaching Hospital. (need to rewrite the reference)

3. F. Chiaffarino, L chatenoud, M. Dindelli, M. Meschia, A. Buonaguidi et al. Reproductive factors, family history, occupation and risk of urogenital Prolapse. European journal of obstetrics \& gynecology and Reproductive Biology 82 (1999) 63-66.
4. Progetto Menopausa Italia study Group. Risk factors for genital prolapse in non-hysterectomies women around menopause. Result from a large cross sectional study in menopausal clinics in Italy. European journal of obstetrics \& gynecology and Reproductive Biology 93 (2000) 135-140.

5. Swift SE, Pound T, Dias JK. Case control study of etiologic factors in the development of severe pelvic organ prolapse. Int urogynecol J Pelvic Floor Dysfunction 2001;12(3):187-92.

6. Park AG, Swash M, Urich M. Sphincture denervation in anorectal incontinence. Gut 1977; 18: 656.

7. Allen RE, Hosker GL, Smith AR, Warrel DW. Pelvic floor damage and child birth: a neurophysiological study. Br J Obstet Gynaecol 1990;97:770-9.

8. Snooks SJ, Swash M, Setchell M, Henry MM. Effect of vaginal delivery in pelvic floor: a five year follow up. Br J Surgery 1990; 771358-1360. Injury to innervation of pelvic floor sphincture musculature in childbirth. Lancet 1984;ii:546-50.

9. Mallett V, Hosker G, Smit ARB, Warrel D. Pelvic floor damage and child birth; a neurophysiologic follow up study Neurourol Urodyne 1994;13;3578.

10. Snooks SJ, Swash M, Henry MM, Setchell M. Risk factors in childbirth causing damage to the pelvic floor innervation. Int $\mathrm{J}$ Colorectal Dis 1986;1:20-4. 